
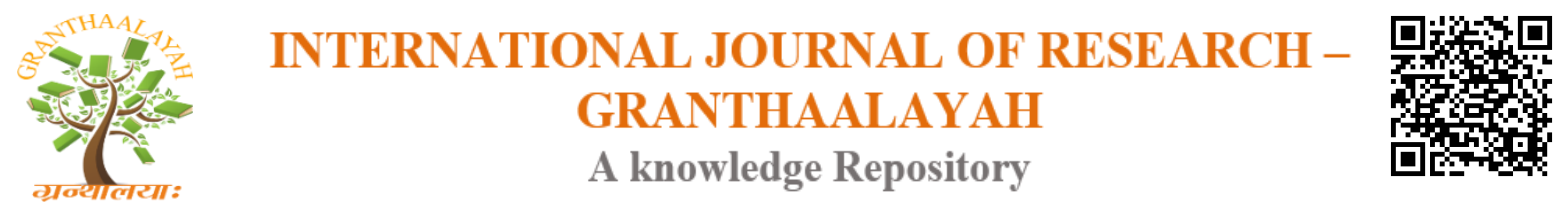

Science

\title{
CHALLENGES AND POSSIBLE IMPROVEMENT OF LIVESTOCK SECTOR IN SOUTH SUDAN: REVIEW PAPER
}

\author{
Taban .A.J. Emmanuel ${ }^{1}$, Kabwanga Ismail Tijjani ${ }^{2}$, Ahmet Çakır ${ }^{3}$ \\ 1,2,3 Faculty of Veterinary Medicine, Ankara University, Turkey
}

\begin{abstract}
South Sudan has agriculture as one of the main contributors of her economy since the vast majority of the households engage in different agricultural activities. Among which is Livestock and it is mostly done on small scale. Cattle keepers are faced with challenges like political instability, civil conflicts, cattle raiding, Continuous uncontrolled pastoralism and poor record keeping by stakeholder with less or no initiatives from gov't to combat the above short comings. The above loopholes among others retard the improvement of the livestock sector. This paper however is meant to highlight the most challenges affecting livestock production, and possible suggestions that can be of use for the organization and the improvement of the livestock sectors. Although South Sudan is considered to be one of the highest Cattle keeping country in Africa, this may be just a mirth once the above issues aren't timely addressed.
\end{abstract}

Keywords: South Sudan; Livestock; Challenges and Improvement.

Cite This Article: Taban .A.J. Emmanuel, Kabwanga Ismail Tijjani, and Ahmet Çakır. (2018). "CHALLENGES AND POSSIBLE IMPROVEMENT OF LIVESTOCK SECTOR IN SOUTH SUDAN: REVIEW PAPER.” International Journal of Research - Granthaalayah, 6(2), 214-223. https://doi.org/10.5281/zenodo.1194652.

\section{Introduction}

South Sudan is a land locked country located in East Africa. It's bordered to the north by the republic of Sudan, to the east by Ethiopia, and to the south by Uganda, Kenya, DRC and CAR to the west [1,2]. South Sudan gained her independence on July 9th 2011 after a referendum [3]. Referrıng to the 2008 national census the population was estimated to be 8.26 million people. However, by Mid- 2010, the population had risen to about $10.05 \mathrm{~m}$ due to the increased return of the of people who had fled from the country due to the endless war and the political instabilities [4]. The recent population was approximated to be 12.7 million. [5]

South Sudan has an estimated total land area of 612,184 $\mathrm{km}^{2}$ [6] [5]. It's rich biodiversity ranges from savanna land, swamps, and rainforests conducive for agricultural production and wildlife.[7]. Over 80\% of the households are involved in agriculture [8, 9] [10] [6] with subsistence farming being dominant [11].South Sudan development plan (SSDP) emphasis is on 
the growth and modernization of the sector $[10,12]$. Although the agriculture sector is dominant, the country's economy largely depends more on the oil sector contrary to her neighbor (Uganda) where agriculture stands as the main contributor to the country's economy [13]. That could be due to the luck of reliable statistic in the sector [10].

Statistics from the Ministry of Agriculture, Forestry, Tourism Animal Resource and Fisheries national herd in 2013 showed that the number of livestock was estimated to be 11.7 million cattle, 12.4 million goats and 12.1 million sheep. [2, 14, 15] .However the total number of livestock in 2015 was approximated to be as 41,979,705 [10, 12] Traditionally, animals are kept not only for home consumption such as milk, hides and meat but also for wealth, social status and pride [16].The government has put more efforts to diversify the economy, especially its agricultural sector where most citizens earn a living. Animals sector is the prominent constitute of agriculture. However, it's encountered by challenges such as intra-inter communal raiding, animal diseases, looting, shortage of water and pasture due to prolong drought and seasonal floods thus interrupting the sector across the country [17]. In 2015, the wide spread of tribal conflict with displacement of nomads and outbreak of diseases have led to livestock crisis [18]. With evidences of the available data, the aim of this paper is to give a review of the livestock sector of South Sudan highlighting its current status, challenges affecting livestock and to give possible recommendation for the improvement.

\section{Livestock}

\subsection{Animal Breed}

The easy adaptation, genetic draft, mutation, and artificial selection has led to the increase of livestock species in the country. The local species are so far the favorite due to their resistance to diseases and harsh weather conditions and are classified basing on their phenotype [2]. There are four major cattle categories; Beef, dual purpose, draught and dairy cattle. The main cattle breed is Sanga an Ethiopian origin it is currently found in the Up Nile, Equatorial and Bahr el Gazal. [19] [20]. The Zebu and Ankole cattle are among the indigenous breeds in the country. Sheep $(12.1 \mathrm{~m})$ and goats $(12.4 \mathrm{~m})$ respectively. The sheep breeds includes:-, Nilotic sheep, it's subdivided into Sudan Nilotic, Toposa sheep, Mangala sheep and the east African small sheep. The goat breeds are; Nilotic goat, subdivided into dwarf goat (Yei), Saanen, East African small goat (Mabenda) and Anglo-Nubian [19]. The Nilotic goats (dwarf goats) are the mainly kept breed in the tropical areas of South Sudan [21].

\section{Animal Distribution}

Animal distribution in Sudan generally depends on the ecological diversity. Locally, large number of animals for example, goats, cows, and sheep are kept in a dry weather, according to the yearly report from the ministry of agriculture [16]. Unfortunately due to outbreak of conflict in 2013 which spread to so many part of the country made livestock camps and rural farms inaccessible hence failing to get detail information about livestock. Table 1. Shows livestock distribution in the 10 states of south Sudan. 
Table 1: Livestock distribution in South Sudan states as per MARF and FAO since 2009[12]

\begin{tabular}{|l|l|l|l|c|}
\hline State & \multicolumn{1}{|c|}{ Cattle } & \multicolumn{1}{c|}{ Sheep } & \multicolumn{1}{c|}{ Goat } & Total \\
\hline Western Equatoria & 675,091 & $1,153,283$ & $1,169,705$ & $2,998,079$ \\
\hline Eastern Equatoria & 888,278 & $1,132,541$ & $1,025,297$ & $3,046,116$ \\
\hline Central Equatoria & 878,434 & $1,153,283$ & $1,265,977$ & $3,297,694$ \\
\hline Warrap & $1,527,837$ & $1,369,005$ & $1,290,045$ & $4,186,887$ \\
\hline Jonglei & $1,464,671$ & $1,207,214$ & $1,400,758$ & $4,072,643$ \\
\hline Upper Nile & 983,027 & 439,741 & 640,209 & $2,062,977$ \\
\hline Unity & $1,180,422$ & $1,754,816$ & $1,487,402$ & $4,422,640$ \\
\hline Lakes & $1,310,703$ & $1,464,421$ & $1,232,282$ & $4,007,406$ \\
\hline Western Bahr El Ghazal & $1,247,536$ & $1,120,095$ & $1,265,977$ & $3,633,608$ \\
\hline Northern Bahr El Ghazal & $1,579,160$ & $1,630,361$ & $1,285,231$ & $4,494,752$ \\
\hline Total & $\mathbf{1 1 , 7 3 5 , 1 5 9}$ & $\mathbf{1 2 , 4 2 4 , 7 6 0}$ & $\mathbf{1 2 , 0 6 2 , 8 8 3}$ & $\mathbf{3 6 , 2 2 2 , 8 0 2}$ \\
\hline
\end{tabular}

However, the above illustrated inform differs from the data estimated in 2014 comprehensive Agricultural development master plan(CAMP) issued by the Ministry of Agriculture, Forestry, Cooperatives and Rural Development and the Ministry of Livestock and Fisheries Industries shows distinctive increase of total livestock population estimated as 41,979,705 [12], with details shown in table 2 below.

Table 2: Livestock population by CAMP Report 2015

[10] [12]

\begin{tabular}{|l|c|}
\hline Livestock type & Population 2014 \\
\hline Goats & $12,307,686$ \\
\hline Pigs & 14,406 \\
\hline Cattle & $17,729,188$ \\
\hline Camels & 23,582 \\
\hline Donkeys & 222,671 \\
\hline Sheep & $11,682,172$ \\
\hline Totals & $\mathbf{4 1 , 9 7 9 , 7 0 5}$ \\
\hline
\end{tabular}

Some data show that South Sudan is the fourth while others consider it to be the sixth country in Africa with the largest livestock population [22].

\section{Major Pastoralist Communities}

Pastoralism is common across African countries ranging from Sahel in the west to the Horn of Africa [23]. In south Sudan, animal rearing is divided mainly into two groups depending on their characteristic and activities; The pastoralists and agro pastoralists with the latter being predominate. In the dry and lowland areas of Eastern Equatoria have the Taposa, Jie, Murle and Nyangatom agro-pastoralists while as the Nile Corridor is inhabited by the Mundari, Dinka and Nuer pastoralists. Pastoralism is common in the above communities possibly as a result of drought and scarcity of pasture [17]. 


\section{Livestock Production System}

The chronic poverty and the rapid growing population calls for the diversification of livestock production systems [24] which are mainly three such as Pastoralist, agro-pastoralist and mixed farming production systems[25].The above systems are viable in south Sudan [17].These system have influence on nature, health and economic development.[26] [24].

\section{Livestock's Products and their uses to the Economy and Owners}

Cattle contribute to $13.57 \%$ of country economy and supply $65 \%$ of red meat [10] [12].This sector is developing rapidly [24] because animals are a prominent source of livelihood, employment and an important asset and it contributes greatly to the country's GDP. Many small holders keep animals not only as a source of food (meat, milk) but also used for paying penalties, bartered for grain, social security, social status, manure, tillage, and transportation, while horn for glue, bone for animal feed and button, and source of biogas and a traditional remedies for disease in a typical African communities[27] [19] [28] [16]

\section{Animal and Animal Products Marketing in South Sudan}

Lake State and Bahr El Ghazal are the main regions that sell cattle to Uganda, Bazi/Kaya to Oraba Koboko and Arua, from Kajo keji to Afoji and Moyo, from Kerwa to Merwa and Yumbe are the major points leading to Uganda markets. Nevertheless some cattle are sold into the DRC and Kenya through Narus and Nadapal routes [29].but due to the outbreak of the civil war livestock marketing is greatly affected [30].

\section{Challenges of the Livestock Sector in South Sudan}

\subsection{Civil War and Political Unrest}

Rampant conflicts on earth has a susceptible effects on environment [31], South Sudan is often described as a chronic complex emergency situation by the Aid agencies [1]. Due to the current conflicts, pastoralists have been clashing with each other and even with farmer [28], livestock crisis continues to increase in south Sudan, as FAO warns on the conflict and instability which has greatly affected the live of agro-pastoralist and pastoralist communities. Currently, the massive displacement, insecurity have led to the fluctuation of animal and animal products prices, increased food staff price and widespread of economic deterioration in the country. This intensive movement of nomads (65\% of population) exposes animals to uncontrolled diseases leading to animal deaths hence livestock crisis and food insecurity. [14, 28]. [18] Unfortunately, there is shortage of data and the danger of nature in warzone areas in the country [31].

\subsection{Disease and Pests}

Livestock diseases create a wider spread of biophysical and socio-economic effect that could be direct and indirect these ranges from local and worldwide [32]. The economic effects are severe because it is expensive and complex to manage in terms of controlling- animal diseases and 
pests. Their impact goes far beyond animal morbidity and Death rate [26]. Studies show that more than $60 \%$ of animal diseases are zoonosis and the new evolving diseases are as high as 75\%. These diseases are transmitted from animals to human in different ways, but the most prevalent way is through animal product consumption [24]. South Sudan's livestock is exposed to number of prevalent diseases, with inclusion:- foot-and-mouth disease (FMD), East Coast fever, peste des petits ruminants (PPR), contagious bovine pleuropneumonia (CBPP) and trypanosomiasis[14]. In 2015, greater Equatoria and greater Bahr el Ghazal regions were the case. Many families and children are detrimentally affected since the diseases have reduced the milk production which they mostly depend on. This situation stands a threat to animal health and productivity. [28]. According to the research done on diseases, most prevalent disease was the east coast fever (ECF) especially in Kajo-Keji followed by Yei counties in Central Equatoria, among other disease outbreak as shown in Table 3. [33]

Ranking by median scores the most importance livestock diseases using proportional piling in Kajo-Keji (a) and Yei (b) counties, southern Sudan.

\section{Diseases}

\begin{tabular}{|l|l|l|c|c|}
\hline Local name Number & English translation & Medium & Range & Number \\
\hline Kajo-keji. & ECF & 25.0 & $3-39$ & 10 \\
Tuling & Ticks & 14.5 & $8-35$ & 8 \\
Masir & Black quarter & 15.0 & $5-35$ & 5 \\
Libuku & Trypanosomiasis & 15.5 & $2-19$ & 8 \\
Miri & Heart water & 17.0 & $8-25$ & 5 \\
Wirja na kuwe & brucellosis & 14.0 & $8-16$ & 5 \\
Yopta & & & & \\
\hline Yei & & & & \\
Kile & Diarrhea & 23.5 & $16-27$ & 4 \\
Lokewani & Black quarter & 21.0 & $6-34$ & 4 \\
Masir & Ticks & 14.0 & $6-33$ & 4 \\
Diburu & ECF & 10.0 & $6-21$ & 3 \\
\hline
\end{tabular}

[33]

\subsection{Inadequate Water Source and Pasture}

Since Livestock production depends primarily on the presence of water and pasture, during the dry seasons pastoralists move to other areas in search for water and pasture while in rainy season they return to their homestead $[17,34]$. The present evidence indicates that there is an inadequate water source in the lowland of Eastern Equatoria region during dry season, while the flood plain ensure enough water supply for the Nuer, Dinka and Mundari. This can lead to high grazing pressure on the natural water points hence degradation of the available sources. [17]. Pastoralist also face graze competition from wildlife like buffaloes [35] 


\subsection{Climate Change and Drought}

The both change in climate, land use and land tenure in East Africa and South Sudan in particular have had severe effect on pastoral lives and Ecology [36, 37]. In the recent 3 decades, south Sudan climate is characterized with hot and drier weather condition hence making it one of warmest countries on earth. Such unreliable climatic changes have resulted to water shortage for agricultural production and lack of pasture for cattle. also, the occasional flooding is one of the climatic challenges leading to displacement of communities, both animals and human diseases and destruction of agricultural production especially in Jonglei and Upper Nile to mention but are few [23, 38]. Changes in weather has also led to internal and even inter-state conflict, for instance the disclosed Sudan conflict with her neighbors on the Nile water[39],

\subsection{Raiding and Conflict}

Pastoral communities in Africa have been characterized with high level of arm violence and under-development. A cattle raiding are a communal violent activity and has taken place for decades South Sudan especially among the Nuer, Dinka and Murle tribes. Cattle raid acts, signifies the change of male youths from adolescent to adult and to increase stock and replace the one lost as a result of disease and thieves. However its scale of frequency in the last five years arousing the attention of United Nations because it involves loss of hundreds of lives and threats to rule of law.[23]

\subsection{High Numbers of Stock}

Animals play a vital role in deforestation since $80 \%$ agricultural land is use for livestock production [40]. Overgrazing of the grasslands has led to lose of vegetation cover leading to exposure of top soil to erosion. [41, 42].The environmental nature in South Sudan can be maintained if the number of the stock is proportional to the capacity of the rangelands. With report from some Sub-Saharan African countries, areas with large number of herds are often overgrazed of grasses and shrubs leaving grass species which are not resistant to drought and climate change hence reduction in livestock production. [17]

\subsection{Poor Veterinary Service and Farming System}

Though South sudan has large number of livestock especially cattle, but due to the system of farming, its produce low milk and meat[43], in the major trade routes there is inadequate facilities and veterinary services [29]. Studies show that there could be a reduction in livestock number due to lack of veterinary service [28].

\subsection{Poor Transport and Marketing Service}

Livestock keepers are being cheated due to lack of information about marketing[29] [11].The livestock transition is at very slow pace in most part of Africa where products are still sold informly by the smallholder. Remoteness of the area limits access to markets and harsh climate though there are high chances of change in the system [24]. 


\section{Conclusion and Recommendation}

\subsection{Veterinary Services and Disease Control Measures}

There is urgent need to boost up veterinary services by government, NGOs and the private sectors. This can help to combat animal diseases, animal breed improvement through breeding and the improvement of animal nutrition as a result of professional training of communities. I suggest that Veterinary services should be accessible from grouped households through counties and all should be equipped with enough facilities. Government should send staff to developed countries to learn user friendly veterinary methods that can apply to low developed countries regarding animal production and animal product manufacturing for sustainability of the system. Private Veterinary practitioners should be encouraged by government through quick and easy to pay loans so as they can be able to equip themselves with better drugs and other required needs to serve the agricultural community in general. Last but not the least, government should put in place more agricultural research institutes that will be able to conduct research regarding animal diseases and disease outbreaks and also conduct other necessary agricultural researches. Such institutes can help to solve and control existing challenges.

\subsection{Animal Production and Marketing Services}

South Sudan has a virgin agro based market that is cuts across all social groups .Use of improved system of livestock production such as ranching, paddocks system and control grazing could help to improve animal production in the country. Laws should be put in place to control or otherwise restrict pastoral activities and control animal raiding. Sensitizing the public against quantity for quality that means considering improved breeds like Holstein, Angus cattle, Brown Swiss etc. of course gradually not doing away with the indigenous breeds. Provision of marketing services for small farmers, for instance in the rural. Provision of milking, cooling and small scale milk and meat processing facilities can help to improve livelihood and household nutrition.

\subsection{Water Source and Management}

Water is an important element for livestock production and increases animal output, however in the lowland of Eastern Equatoria, water scarcity during dry season is high. I call upon government to construct ground water reservoirs, dig wells, dams, widening of available sources and water treatment, and drilling of boreholes to provide water for the animals and households in general. These methods can help to address problems of climate changes and water shortages

\subsection{Improvement in Agricultural Records}

It is essential that a livestock census or large scale sample survey should be undertaken as soon as possible and this should be a routine after a specified period to keep the country updated. Such data can help to show the country's economy, food and nutrition status. Government can use such data to promote the country on the international scene or even solicit international funds where necessary. 


\subsection{Training of Traders and Other Stakeholders}

Farmers, traders and other stakeholders have limited knowledge about animal production, animal product handling and marketing as it has been compiled by many researchers. Traders need to be trained on animal disease detection to avoid sale of contaminated products to people, selection and weight assessment, and pricing of animals suitable for slaughter, Currencies and exchange rates, record keeping, policies governing movement of livestock and movement permit, livestock ware fare, how to access credits from financial institutions, formation of trade unions and the existence of internal and external opportunities in the export markets. Once the above recommendations are put into practice, South Sudan has a great potential to develop and champion the livestock sector in the region and beyond.

\section{References}

[1] Catley, A., et al., Participatory diagnosis of a chronic wasting disease in cattle in southern Sudan. Preventive Veterinary Medicine, 2001. 51(3-4): p. 161-181.

[2] Baigo, A.F., Healthy Livestock- Healthy People - Sustainable Development Republic of South Sudan.National Ministry of Animal Resources and Fisheries, 2013: p. 20.

[3] Knox, C., The Secession of South Sudan: A Case Study in African Sovereignty and International Recognition. 2012.

[4] The National Bureau of Statistics, T.R.o.S.S., Southern Sudan Centre for Census, Statistics and Evaluation. Global Environmental Change, 2011(Dataset Records for Southern Sudan Centre for Census, Statistics and Evaluation).

[5] (www.Worldometers.info, W., South Sudan Population. Worldometers (www.Worldometers.info), 2016.

[6] Chokerah, J. and S. Horvath, Investing in Agriculture for Food Security and Economic Transformation. 2012, UNDP South Sudan, Juba. Available at: http://www. ss. undp. org/content/dam/southsudan/library/Reports/southsudanotherdocuments/Investing\% $\quad 20 \mathrm{in} \%$ 20Agriculture \% 20for\% 20Food\% 20Security.

[7] Sikainga, M.e.D.S.J.L.S.R.O.C.A.A., South Sudan. Encyclopaedia Britannica Inc, 2016: p. 2.

[8] Omer, A.M., Water resources and freshwater ecosystems in Sudan. Renewable and Sustainable Energy Reviews, 2008. 12(8): p. 2066-2091.

[9] Omer, A.M., Biomass energy potential and future prospect in Sudan. Renewable and Sustainable Energy Reviews, 2005. 9(1): p. 1-27.

[10] (ICPALD), I.C.f.P.A.L.D., The Contribution of Livestock to the South Sudan Economy. INTERAFRICAN BUREAU FOR ANIMAL RESOURCES, 2016: p. 12.

[11] Idris, B., Livestock Marketing in Eastern and Central Sudan. 2007, MDTF-National Sector Policy Note, Sudan Multi Donor Trust Funds, Technical Secretariat, World Bank, Khartoum.

[12] Diana Onyango, G.O., Robert Too and Rachael Masake, The Contribution of Livestock to the South Sudan Economy. African Union InterAfrican Bureau for Animal Resources. IGAD Center for Pastoral Areas and Livestock Development ( ICPALD), 2015: p. 34.

[13] Tijjani, K.I., Dairy Cattle and Dairy Industry in Uganda: Trends and Challenges. Research Journal of Agriculture and Forestry Sciences, 2015. Vol. 3((10), 14-18): p. 18.

[14] Green, A., Cows and conflict: South Sudan's "slow motıon" livestock crisis The inside story on emergencies (IRIN), 2015(Food analysis).

[15] Doki, C., South Sudan, Where Livestock Outnumbers People and the Environment Suffers. (IPS) Inter Press Service News Agency, 2014. 
[16] Ibrahim, A.M., X. Shiwei, and Y. Wen, The Impact of Social Factors of Rural Households on Livestock Production and Rural Household Income in White Nile State of Sudan. International Journal of Agricultural and Food Research, 2013. 2(4).

[17] Abate, A. Livestock production challenges in the rangelands ecosystem of South Sudan. in Workshop on Environmental Management Plan for Post-conflict Sudan, Raha Hotel, Juba, South Sudan, nd October. 2006.

[18] FAO, South Sudan Livestock Crisis. Food and Agriculture Organization of United Nations (FAO), 2015: p. 5.

[19] Alabi, T., To Improved Cattle, Sheep, Goat and Poultry Husbandry Practices for Smallholder Farmers in South Sudan. Miistry of Livestock and Fisheries, South Sudan 2016: p. 51.

[20] Gout, W.J.F., The Measurement of Nilotic Cattle in South Sudan. 2015, Sudan University of Science and Technology.

[21] Atta, M., et al., Reproductive performance of Sudan Nilotic does fed pelleted molasses and mash sorghum based diets. Small ruminant research, 2012. 104(1): p. 99-103.

[22] UN, F., South Sudan - Economy. GlobalSecurity.org 2013.

[23] Richardson, T., Pastoral violence in Jonglei. American University, December, 2011.

[24] Smith, J., et al., Beyond milk, meat, and eggs: Role of livestock in food and nutrition security. Animal Frontiers, 2013. 3(1): p. 6-13.

[25] Cecchi, G., et al., Geographic distribution and environmental characterization of livestock production systems in Eastern Africa. Agriculture, ecosystems \& environment, 2010. 135(1-2): p. 98-110.

[26] Thornton, P.K., Livestock production: recent trends, future prospects. Philosophical Transactions of the Royal Society B: Biological Sciences, 2010. 365(1554): p. 2853-2867.

[27] Ahmed, A.G.M., The social uses of livestock among pastoralists in Sudan: Food systems, stores of value, wealth, power, and authority. CMI Sudan Working Paper, 2014.

[28] (FAO), F.a.A.O.o.U.N., South Sudan. Livestock strategy Paper Food and Agriculture Organization of United Nations (FAO), 2015: p. 7.

[29] King, A. and E. Mukasa-Mugerwa, Livestock Marketing in Southern Sudan: With Particular Reference to the Cattle Trade between Southern Sudan and Uganda. OAU and the Pan African Programme for the Control of Epizootics (PACE), 2002.

[30] Yacob Aklilu Gebreyes , G.B.L., Luka Biong Deng,Shaif Abdullahi, The Impact of Conflict on the Livestock Sector in South Sudan Food and Agriculture Organization of United Nations (FAO), 2016: p. 16-118.

[31] Gorsevski, V., M. Geores, and E. Kasischke, Human dimensions of land use and land cover change related to civil unrest in the Imatong Mountains of South Sudan. Applied geography, 2013. 38: p. 64-75.

[32] Perry, B. and K. Sones, Global livestock disease dynamics over the last quarter century: drivers, impacts and implications. Rome, Italy: FAO.(Background paper for the SOFA 2009), 2009.

[33] Malak, A., et al., Prevalence of livestock diseases and their impact on livelihoods in Central Equatoria State, southern Sudan. Preventive veterinary medicine, 2012. 104(3-4): p. 216-223.

[34] Ayana, E.K., et al., Examining the relationship between environmental factors and conflict in pastoralist areas of East Africa. Science of The Total Environment, 2016. 557: p. 601-611.

[35] Byaruhanga, C., et al., Using participatory epidemiology to investigate management options and relative importance of tick-borne diseases amongst transhumant zebu cattle in Karamoja region, Uganda. Preventive veterinary medicine, 2015. 122(3): p. 287-297.

[36] Sulieman, H. and N. Elagib, Implications of climate, land-use and land-cover changes for pastoralism in eastern Sudan. Journal of Arid Environments, 2012. 85: p. 132-141.

[37] Comte, J.-C., et al., Challenges in groundwater resource management in coastal aquifers of East Africa: Investigations and lessons learnt in the Comoros Islands, Kenya and Tanzania. Journal of Hydrology: Regional Studies, 2016. 5: p. 179-199. 
[38] Sosnowski, A., et al., Remote regions, remote data: A spatial investigation of precipitation, dynamic land covers, and conflict in the Sudd wetland of South Sudan. Applied Geography, 2016. 69: p. 51-64.

[39] Selby, J. and C. Hoffmann, Beyond scarcity: rethinking water, climate change and conflict in the Sudans. Global Environmental Change, 2014. 29: p. 360-370.

[40] Weindl, I., et al., Livestock and human use of land: Productivity trends and dietary choices as drivers of future land and carbon dynamics. Global and Planetary Change, 2017. 159: p. 1-10.

[41] Bo, T.-L., L.-T. Fu, and X.-J. Zheng, Modeling the impact of overgrazing on evolution process of grassland desertification. Aeolian Research, 2013. 9: p. 183-189.

[42] Ibáñez, J., J. Martínez, and S. Schnabel, Desertification due to overgrazing in a dynamic commercial livestock-grass-soil system. Ecological Modelling, 2007. 205(3-4): p. 277-288.

[43] Lupai, J.K., South Sudan potentially the region's breadbasket. SudanTribune 2011.

*Corresponding author.

E-mail address: taban2013alex@ gmail.com 